\title{
Wave-current-surge interaction in a changing climate over a shallow continental shelf region
}

\author{
Bishnupriya Sahoo a,b, Trilochan Sahoo a, Prasad Kumar Bhaskaran ${ }^{\mathrm{a}, *}$ \\ a Department of Ocean Engineering and Naval Architecture, Indian Institute of Technology Kharagpur, Kharagpur 721 302, West Bengal, India \\ ${ }^{\mathrm{b}}$ Yantai Institute of Coastal Zone Research, Chinese Academy of Sciences, Yantai, 264 003, PR China
}

\section{A R T I C L E I N F O}

\section{Article history:}

Received 24 February 2021

Received in revised form 1 June 2021

Accepted 25 June 2021

Available online 30 June 2021

\section{Keywords:}

Extreme waves

Storm surge

Climate change

Bathymetry

\begin{abstract}
A B S T R A C T
Wave climate over the North Indian Ocean region experienced a paradigm shift in the recent past, indicating an increase in the extremes. Wind-waves and swell climatology have shown an increasing trend over this region, having direct implications on the coastal zone dynamics surrounding the mainland and island features. The present study aims to investigate the wave-current-surge interaction characteristics over a shallow continental shelf region between India and Sri Lanka using the state-ofart coupled ADCIRC-SWAN model. In particular, a case study performed during tropical cyclone Madi (2013) demonstrates the extreme wave-current-surge interaction mechanism over varying nearshore bathymetric features. Study investigated the wave reflection and transmission characteristics in both the absence and presence of the proposed navigation channel (known as Sethusamudram project) in a coastal vulnerability context. Construction of the channel may result in westward shift of hazardous coastal water zones attributed to storm tides. The navigation channel expects to enhance both extreme waves and storm surge by $1 \%$ and $4 \%$, respectively. Synthetic experiments, considering an increase in sea level rise by $0.4 \mathrm{~m}$ expected by 2050 , indicate that wave activity can increase by $3 \%$ with marginal variations in storm tide. Simulations performed with a $7 \%$ rise in tropical cyclone intensity reveals a substantial increase in storm surge (10\%) and significant wave (20\%) heights along the coastal belt.
\end{abstract}

(C) 2021 Elsevier B.V. All rights reserved.

\section{Introduction}

Wind-wave climate over the global ocean basins have experienced a paradigm shift in the recent past, indicating a clear increase in the extremes over the North Indian Ocean (NIO) basin (Bhaskaran et al., 2014; Gupta et al., 2015). The annual mean significant wave height has increased at a rate of $0.27 \mathrm{~cm} / \mathrm{year}$ (Sreelakshmi and Bhaskaran, 2020a). Unlike the past decades, the frequency of tropical cyclones (TCs) over AS (Arabian Sea) showed an increasing trend (Murakami et al., 2017). Study reported around $600 \%$ increase in TC intensity over the Bay of Bengal (BoB) basin during the past decade (Sahoo and Bhaskaran, 2016). There are different case studies that demonstrated increased coastal vulnerability due to storm surges, extreme windwaves and sea level rise. For example, the studies by Barman et al. (2016), Sahoo and Bhaskaran (2018) for the Odisha coast; Nayak et al. (2013) for Kalpakkam coast in Tamil Nadu; Behara et al. (2017) for coastal Sri Lanka; Pramanik et al. (2015) for the east coast of India are notable. In context to coastal vulnerability, the geographical region bounded between the south Indian mainland and Sri Lanka (Fig. 1), is well-known for its rich

\footnotetext{
* Corresponding author.

E-mail address: pkbhaskaran@naval.iitkgp.ac.in (P.K. Bhaskaran).
}

biodiversity comprising about 3600 species of flora and fauna and 117 rare coral species (Parthasarathy and Natesan, 2015), is relatively resilient. Geographically, this region is shallow, narrow, and located over the wider continental shelf of the southern Indian landmass. The sheltering effect of Sri Lankan landmass constraints higher wave activity over this region. There are hardly any studies performed over this region for wave-current-surge interaction due to its coastal resilience. However, the coastal belts bordering this region have been impacted by recent extreme oceanic events such as tsunami, storm surges, extreme waves, and sea-level rise (Parthasarathy and Natesan, 2015; Pramanik et al., 2015; Behara et al., 2017).

Several studies have investigated the extreme wave characteristics over the North Indian Ocean region. Some of the studies include Bhaskaran et al. (2000, 2004, 2013a,b, 2015), Bhaskaran (2010, 2019), Gayathri et al. (2015, 2016), Gupta et al. (2015, 2017), Murty et al. (2016, 2019, 2020), Nayak et al. (2012, 2013), Nayak and Bhaskaran (2014), Padhy et al. (2008), Patra and Bhaskaran (2016a,b), Patra et al. (2019), Poulose et al. (2017), Samiksha et al. (2017) and Umesh et al. (2019). Literature survey provides no background studies that links impact of climate change on coastal hydrodynamics for the shallow shelf region between India and Sri Lanka. Increased tropical cyclone activity in the Arabian Sea and Bay of Bengal regions, sea-level rise 


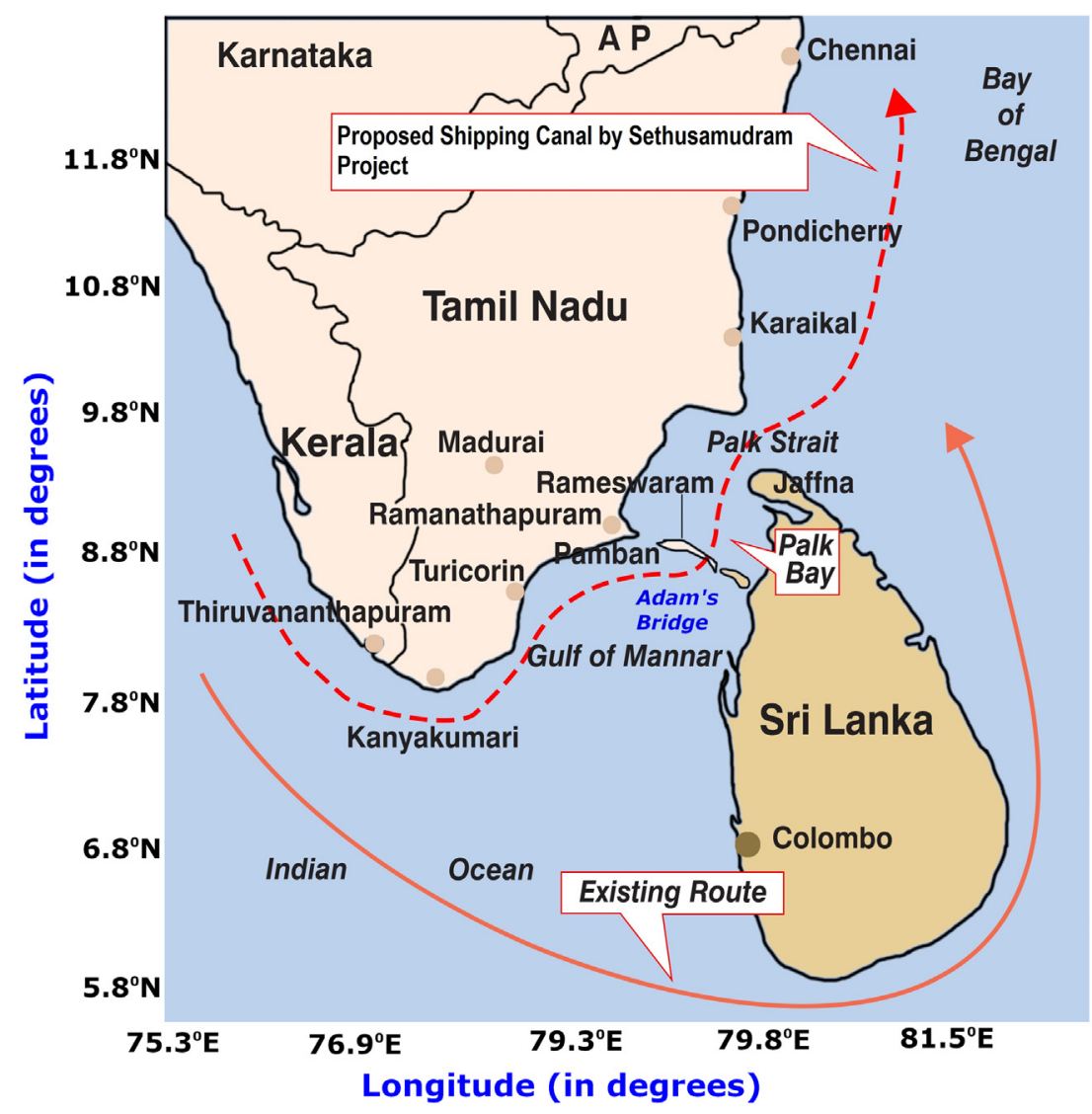

Fig. 1. Gulf of Mannar between the Indian mainland and Sri Lanka. The Sethusamudram project proposed navigation channel through Adam's bridge is shown.

(SLR) and increasing extreme swell activity warrants a detailed wave-current-surge interaction study and their projections in a changing climate scenario for the coastal community.

Furthermore, this domain has strategic importance in context to the shipping lane. In 2005, the Sethusamudram Shipping Canal Project was proposed by the Ministry of Shipping, Government of India to construct a continuous navigable sea route around the Indian peninsula linking the Arabian Sea to the Bay of Bengal through Adam's Bridge (please refer to Fig. 1) instead the vessels bypassing Sri Lanka thereby saving the voyage time. The water depths in the proposed location are shallow and that requires dredging to maintain optimum water depth for navigational requirements. However, the proposed modification in the existing bathymetry over this region due to dredging activity can also result in changing nearshore hydrodynamics due to wave-current-surge interaction characteristics.

In a global perspective, there are various mathematical studies (Mandal et al., 2013; Das et al., 2016a, 2018; Kaligatla et al., 2017; Behera et al., 2018; Kar et al., 2019, 2020), numerical (Ris et al., 1999; Millar et al., 2007; Gorrell et al., 2011; Vlasenko and Stashchuk, 2007; Dietrich et al., 2013; Cunha, 2015; Williams et al., 2015). On the other hand, experimental studies (Bondzie and Panchang, 1993; Plant et al., 2009; Morelissen et al., 2003) addressed both regional and global wave-current-surge characteristics over complex bathymetry. Lee and Ayer (1981) and Kirby and Dalrymple (1983) postulated that nearshore dynamics are highly sensitive to submarine depressions in coastal waters; the diffraction model by Lee et al. (2007) and unidirectional wave model by Kar et al. (2018) derived the changes in the incident and transmitted wave characteristics over submarine pits (often called trenches in mathematical studies). Numerical modeling studies depicted the nearshore wave-surge transformation properties considering the effect of mangroves (Parvathy and Bhaskaran, 2017a, 2017b, 2019) and gradients in bathymetric profile (Sahoo and Bhaskaran, 2018; Sahoo et al., 2019) during extreme weather conditions. Similarly, climate change has a critical impact on the wave climate and storm surge characteristics (Das et al., 2016b; Malik and Abdalla, 2016; Jisan et al., 2018).

Considering the impacts of climate change in the NIO basin and anthropogenic interventions in the intermediate region between India and Sri Lanka, this study focused on two issues. Firstly, the characteristics of wave-current-surge interaction in a changing climate scenario by considering increased tropical cyclone intensity and sea-level rise. Secondly, the study investigated the impact of bathymetric profile on wave-current-surge interaction upon the proposed navigational channel over the shallow bathymetry between India and Sri Lanka. The present study implemented the state-of-art coupled ADCIRC-SWAN model to simulate the wave-current-surge interaction considering cyclone Madi (2013) as a case study. To understand the underlying dynamics in wave-current-surge interaction in the context of the proposed navigation channel, the present study constructed a hypothetical channel over the actual bathymetry of the study domain. Hypothetical water depths in the presence of the navigation channel is used to simulate Madi (2013) induced storm surge and extreme waves. Simulated results analyzed the combined effects of SLR, increased TC intensity in a changing climate for the region of interest considering the modified bathymetry with the proposed navigation channel. The organization of the paper is as follows: Section 2 deals with the Data and Methodology covering aspects on the experimental setup of the coupled model and various numerical experiments on wave-current-surge interaction. Additionally, the section also includes the design of hypothetical bathymetry with the proposed navigation channel and synthetic experiments considering futuristic impact of climate change. The 


\section{(a)}

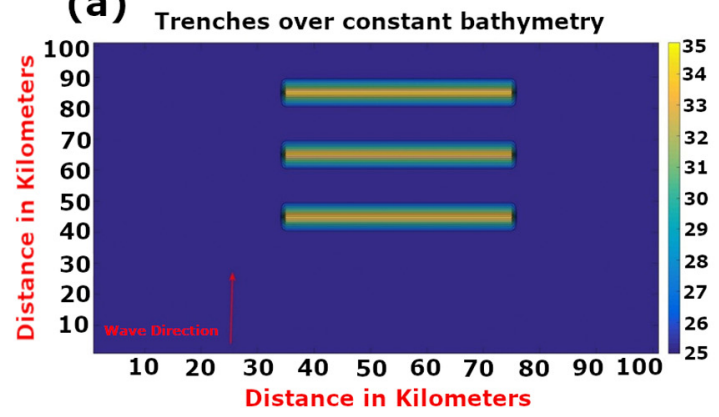

(b)
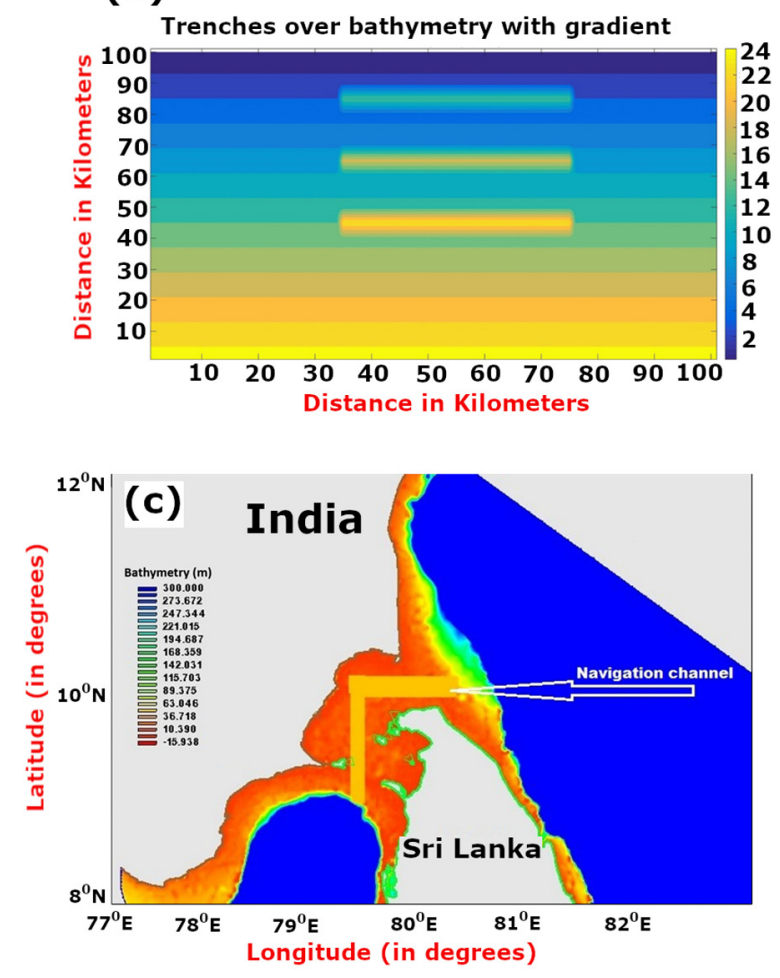

Fig. 2. Trench over a constant bathymetry, (b) Trenches over bathymetry with a gradual slope, and (c) Modified bathymetry with hypothetical navigation channel passing through Gulf of Mannar, Adam's Bridge, Palk Bay, and Palk Strait between the Indian mainland and Sri Lanka.

Results and Discussion in Section 3 illustrate wave-current-surge interaction characteristics over different bathymetric configurations in a changing climate. Finally, Section 4 covers the overall Summary and Conclusion of the present study.

\section{Data and methodology}

The study focused on wave-current-surge dynamics over a shallow continental shelf region between India and Sri Lanka. Fig. 1 depicts the water body separating the Indian landmass and Sri Lanka referred as Gulf of Mannar, Adam's Bridge, Palk Bay, and the Palk Strait. The Gulf of Mannar envelopes the west coast of Sri Lanka and the southeastern tip of India, and the Palk Bay lies along the northern strip of Sri Lanka and the southeast coast of India. The Gulf of Mannar and Palk Bay are separated through Adam's Bridge (also known as Ramsetu), which is a narrow chain of submerged islands and reefs. The hypothetical border between the Palk Bay and Bay of Bengal referred as the Palk Strait. The present study performed numerical experiments using the coupled ADCIRC-SWAN model to understand the extreme water level characteristics over this region during the extreme event Madi (2013), the only tropical cyclone that passed through the study region. A low-pressure system in the Bay of Bengal was detected as cyclone Madi on November 30, 2013. Further, on December 5, it was a deep depression. The low-pressure system transformed into a very severe cyclonic storm and thereafter it weakened into a depression making multiple landfall at Tamil Nadu coast in India and passing through Palk Strait on December 12, 2013. Madi made landfall twice along the southern tip of the Indian mainland on December 12, 2013. Winds over southeastern India and northeastern Sri Lanka experienced a maximum sustained wind speed of about 25 knots during landfall. Meteorological forcing to the coupled model used derived winds from Holland wind formulation (Holland, 1980) and based on JTWC best-track estimates for Madi. The following sections elaborate on the coupled ADCIRC-SWAN model, experimental setup and the configurations of synthetic experiments (considering hypothetical bathymetry with the proposed navigational channel and future SLR along with increased tropical cyclone intensity) carried out in the present study.

\subsection{Coupled ADCIRC-SWAN model}

The ADCIRC (Advanced Circulation) model, developed is being widely used for simulating water levels including storm surges (Dietrich et al., 2011; Bender et al., 2012; Xie et al., 2016; Bhaskaran et al., 2013a,b; Murty et al., 2014, 2016). ADCIRC-2DDI, a two-dimensional depth-integrated model used in the present study, solves the generalized wave continuity equations facilitating unstructured triangular mesh with a continuous Galerkin finite element method. The unstructured triangular mesh better resolves the complex geometry and bathymetry. SWAN (Simulating Waves Nearshore) a third-generation spectrum wave model Ris et al. (1999) solves the wave-action balance equation by integrating the 2D wave energy spectrum in both frequency and direction space.

In the coupled ADCIRC-SWAN model (Dietrich et al., 2011); ADCIRC computes the water level and exchanges current information to the tightly coupled SWAN model that runs on the same unstructured grid and wind field. SWAN exchanges the computed wave radiation stresses to ADCIRC to update the predicted water level and currents. Limiters on spectral propagation velocities controls the abnormal wave growth that accounts due to sharp gradients in bathymetry (Dietrich et al., 2013). Model uses various options of model physics such as Komen and Janssen formulation for wind-wave growth (Cavaleri and Rizzoli, 1981), depth-induced wave breaking (Battjes and Janssen, 1979) with varying breaking index, JONSWAP and Madsen bottom friction formulations (Hasselmann et al., 1973; Madsen et al., 1988).

In this present study, the coupled ADCIRC-SWAN model computed the resultant water level, wave characteristics, and depthintegrated currents on high-resolution flexible mesh varying between $200 \mathrm{~m}$ in the nearshore regions and relaxing up to $15 \mathrm{~km}$ in the offshore regions. Bathymetry for the study domain was obtained from GEBCO and the tidal harmonics along the open ocean boundary was derived from the Le-Provost tidal database. A preliminary analysis indicated that a time step of $5 \mathrm{~s}$ and $10 \mathrm{~min}$ would suffice stable ADCIRC and SWAN computations. Information pertaining to ADCIRC computed water level and currents and SWAN computed wave radiation stresses exchange at every one-hour interval. Table 1 provides more details on the model configuration used for the present study. Simulated wave parameters validated with the fifth generation ECMWF atmospheric reanalysis (ERA5) products (C3S, 2017) derived from ensemble numerical models and altimeters. 
Table 1

Model configuration of the coupled ADCIRC-SWAN setup.

\begin{tabular}{ll}
\hline Model Setup & Details \\
\hline $\begin{array}{l}\text { Grid type } \\
\text { Mydrological input }\end{array}$ & $\begin{array}{l}\text { Flexible finite element mesh } \\
\text { Open boundary tidal forcing from Le-Provost Tidal database } \\
\text { Holland wind formulation using JTWC best-track estimates }\end{array}$ \\
\hline Experimental Setup & \\
\hline Bottom Friction & Hybrid friction for ADCIRC and JONSWAP for SWAN \\
Simulation details & $\begin{array}{l}\text { Simulation of cyclonic waves and storm tide: coupled ADCIRC-SWAN } \\
\text { simulation }\end{array}$ \\
& $\begin{array}{l}\text { Inputs: Le-Provost tide, Wind- Holland formulation, 6-hourly interval, Tides: } \\
\text { Representative tidal constituents along the open boundary } \\
\text { Timestep of integration for ADCIRC and SWAN: } 5 \text { sec and 10 min respectively. }\end{array}$ \\
\hline Coupling time step & Interval for mutual exchange of information between ADCIRC and SWAN- 1 h. \\
\hline
\end{tabular}

(a)

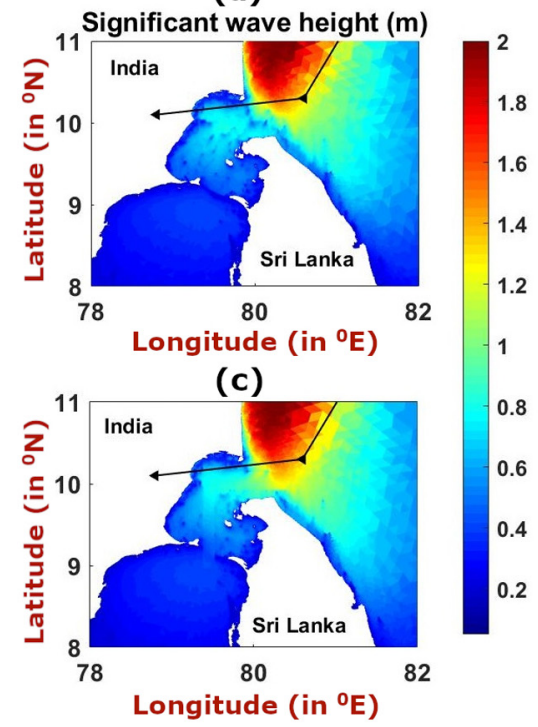

(b)

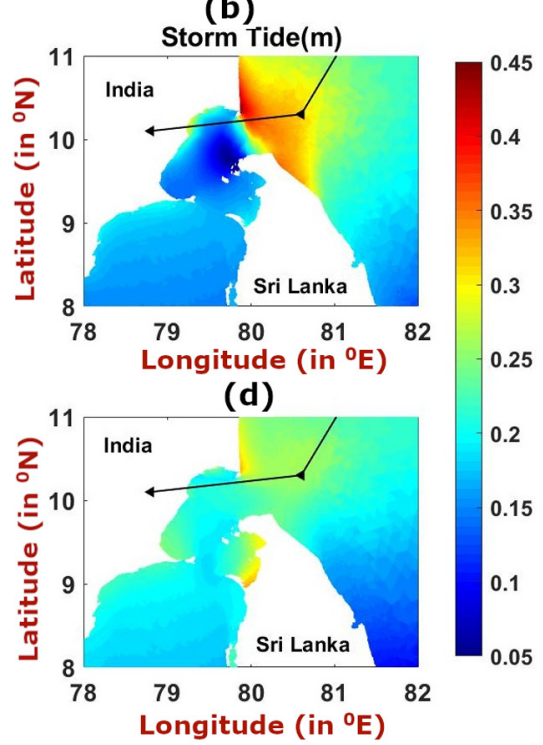

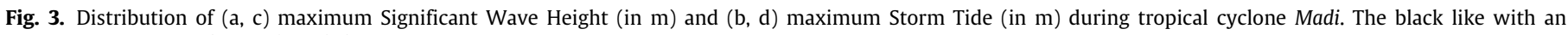
arrow represents Madi's track and direction.

\subsection{Hypothetical navigation channel through Adam's bridge}

The water depth in the study region varied between 3-15 m, wherein, the average water depth near Adam's Bridge is less than $5 \mathrm{~m}$. In order to understand the resulting changes in nearshore hydrodynamics due to bathymetric variations by dredging, the study considered a hypothetical navigation channel (Fig. 2c) of 18 $m$ water depth over the actual bathymetry. Suitable modifications were accounted in the model mesh structure that accommodates the presence of navigation channel and used for another set of study that considered the wave-current-surge interaction due to varied bathymetry. The navigation channel bypassing through Adam's bridge and the Palk Bay is hypothetical and may differ from the actual design. For the information of readers, the SWAN model accounts for both wave reflection and diffraction mechanisms. Study designed a set of numerical experiments considering the idealized bathymetry of constant depth (Fig. 2a) and bathymetry with a uniform gradient of 1:4 (Fig. 2b). In addition, the standalone SWAN model simulated wave characteristics using the idealized bathymetry considering different cases such as without depression, and nearshore depressions with variable water depth, width, and numbers as shown in Fig. 2a-b. Results derived from these idealized experiments validated with relevant mathematical formulation (Kar et al., 2018). For the idealized cases, the bathymetric depression is termed as trenches hereafter.

Reflection and transmission coefficients are calculated to understand the impact of navigation channel on wave propagation characteristics. The reflection coefficient is calculated using the formula $K_{r}=H_{r} / H i$, where $H_{i}$ and $H_{r}$ represent the respective incident and refracted significant wave heights with/without the proposed navigational channel. Similarly, the transmission coefficient is estimated using the formula $K_{t}=\mathrm{H}_{t} / \mathrm{Hi}$. Further, the reflection and transmission coefficients plotted versus the nondimensional wavenumber $k h$, where $k$ is the wavenumber and $h$ is the corresponding water depth. Since the coupled ADCIRC-SWAN model outputs do not include wavenumber, the following basic calculations estimated the wavenumber from the time-period obtained from the coupled model. In shallow water, $c=\pi / T=$ $\sqrt{g h}, k h=(2 \pi / \lambda) h=(2 \pi / T) \sqrt{h / g}$. To estimate the reflection and transmission coefficients, the incident wave heights $H_{i}$ is measured at point A (Fig. 2c) during the jth time step whereas, the reflected and transmitted wave heights are measured at locations $B$ and $C$ during $(\mathrm{j}+1)$ th time step.

\subsection{Wave-current-surge propagation characteristics in a changing climate scenario}

A very recent study by Singh et al. (2021) reported about $26 \%$ increment in the intensity of landfalling Extremely Severe Cyclonic Storms (ESCS) over the North Indian Ocean (NIO) region during the study period 1990-2020. It indicates that on an average the increment per decade is around $8 \%$. Sahoo and Bhaskaran $(2016,2017)$ have projected cyclone intensity in terms of PDI (Power Dissipation Index) on a decadal scale. The PDI during the 
decade 2010-2019 have an absolute increment of 7\% compared to the past decade (2000-2009). However, during the time scales 2000-2009 and 2010-2019, the estimated increase in PDI were $9 \%$ and $6 \%$ increment respectively. Kusche et al. (2016) estimated 37 (40) cm absolute SLR by the year 2050 under the RCP 4.5 (8.5) scenario. Besides, the increased swell activity generated from Southern Ocean can modulate and modify the wind-wave characteristics over the BoB region (Sreelakshmi and Bhaskaran, 2020b). In the present study, the model configuration used the futuristic scenario by considering the absolute SLR of $40 \mathrm{~cm}$. In addition, the model domain accounted for increased swells arriving from the Southern Ocean region. The wind field for cyclone Madi was increased by $7 \%$ (accounting for increased projected TC intensity) to model the enhanced impact of storm surge and wave heights. Numerical experiments considered both with and without the hypothetical navigation channel to understand the characteristics of coastal hydrodynamics in a changing climate scenario.

\section{Results and discussion}

This section elaborates on the wave-current-surge characteristics for the intermediate waters of India and Sri Lanka during Madi. The analysis focused on the projected hydrodynamics in a changing climate scenario by considering the increased intensity of TC and SLR effects. The subsequent section analyzes and discuss the influence of proposed Sethusamudram project on the extreme wave conditions and surge dynamics in the study area.

\subsection{Wave-current-surge interaction during TC Madi}

Fig. 3a-b depicts the spatial distribution of maximum significant wave height and storm tide simulated using a coupled ADCIRC-SWAN model during cyclone Madi. Simulated results decipher that the southeast coast of India was worst affected by extreme waves being at the right of the Madi track. An interesting study by Samiksha et al. (2017) investigated the wave-current interaction using a coupled ADCIRC+SWAN model for a very severe cyclonic storm Hudhud that made landfall at Visakhapatnam on the east coast of India during October 2014. This location is north of the present study area that investigated the wavecurrent-surge interaction associated with cyclone Madi (2013). In addition, Samiksha et al. (2017) validated model computed wave and storm surge heights with measurements near Visakhapatnam, the landfall point. The coupled model computed maximum surge height was $1.2 \mathrm{~m}$ that matched well with the maximum surge height of $1.4 \mathrm{~m}$ measured off Visakhapatnam. Their study (Samiksha et al., 2017) showed that waves contributed nearly $0.25 \mathrm{~m}$ to the total water level elevation during Hudhud event. For waves, propagating perpendicular to the coast after crossing the shelf region and for currents directed in the southwest direction, study revealed that wave heights reduced due to wave-current interaction. However, the wave heights increased on the left side of the cyclone track when waves and currents opposed each other (Samiksha et al., 2017). In the present study, reduced significant wave height (Fig. 3a) is seen surrounding the landfall point following decreased cyclone intensity and shallow water depths. Due to shallow bathymetry and low tidal range, the wave-current interaction in the study area is different as compared to the Visakhapatnam coast. However, the significant wave heights are higher along the right side compared to left side of the cyclone track. The maximum significant wave height off Sri Lanka was about $0.8 \mathrm{~m}$ at the northern tip of the island, whereas it was about $0.5 \mathrm{~m}$ near the northeast coast. The western and southern regions of the island barely experienced the cyclone-induced waves. $\mathrm{Cy}$ clone Madi resulted in about $0.5 \mathrm{~m}$ storm tide along the east coast of Tamil Nadu, India between $10-11^{\circ} \mathrm{N}$ latitudes (Fig. 3b). Almost
$0.3 \mathrm{~m}$ of storm tide above mean sea level is evident near the landfall location. The storm tide varied between $0.3-0.35 \mathrm{~m}$ along the northeast coast of Sri Lanka during this event. Study show no much effect along the northern and the northwestern regions of Sri Lanka by high storm surge, being on the left side of Madi track. Shallow water depths at Palk Strait might have restricted the storm surge to propagate further westward. During this event, the model-simulated highest current speed was around $1 \mathrm{~m} / \mathrm{s}$ near the Palk Strait attributed due to shallow bathymetry.

Real-time validation is one of the shortcomings of this study. The wave-rider buoys at Colachel and Tuticorin in the study domain were not available during the study period. Hence, the study could not produce any measured data on water level and wave parameters for validation purpose. Study used the ERA5 wave parameters obtained at $0.5^{\circ}$ spatial and hourly temporal intervals. Fig. 4a validates the spatial variability of significant wave height. Maximum significant wave heights obtained from the coupled ADCIRC-SWAN model for the study domain showed a reasonable correlation with the ERA5 data products during TC Madi. The domain averaged Root Mean Square Error (RMSE) for the maximum significant wave height was $0.1 \mathrm{~m}$. A negative estimate for relative bias signifies slight underestimation by the coupled model. Domain averaged relative variance (0.2) for windwaves is within the reasonable limit. However, the study could not validate the modeling results along the nearshore regions due to inherent data gaps in the ERA5 product. Fig. 4b depicts the regression plots for significant wave heights, wave direction, and peak period. Time series of significant wave heights at various grid points of the domain compared with the ERA5 data resulted in a regression coefficient of 0.76 that is statistically significant. The regression coefficient improved to 0.82 and 0.85 in the case of space and time-averaged significant wave heights. Spatial average wave direction obtained from the coupled model produced a regression coefficient of 0.78 with the ERA5 data that is statistically significant. The validation exercise showed a regression coefficient of 0.68 for the peak wave period.

The water level simulated with the ADCIRC model is a well calibrated over the global ocean basins. For example, ADCIRC computed water levels over a complex bathymetry in the head Bay of Bengal showed a high degree of match with observations (Rose and Bhaskaran, 2017a,b). Similarly, the coupled ADCIRC-SWAN model has proven its efficiency for water levels and significant wave heights during extreme weather events (Murty et al., 2014, 2016). Studies conducted for the head Bay region had successfully implemented the SWAN model to investigate the complex effect of mangroves in nearshore wave transformation during both fair and extreme weather conditions (Parvathy and Bhaskaran, 2017; Parvathy et al., 2017; Parvathy and Bhaskaran, 2019). In addition, the numerical results obtained were also compared with the past studies. The highest high tide and lowest low tide at Kanyakumari vary between $0.1 \mathrm{~m}$ to $1 \mathrm{~m}$ during the northeast and southwest monsoon seasons (Gurumoorthi and Venkatachalapathy, 2016). The significant wave heights vary between 1-1.5 m during December in fair weather conditions (Hentry et al., 2013). The simulated results for the cyclonic case considered in the present study provides necessary confidence to carry out further detailed analysis.

\subsection{Influence of bathymetry on wave-current-surge interaction}

Bottom features can critically influence the nearshore wavecurrent-surge dynamics. The navigation channel in the study region might potentially affect the present wave-current-surge dynamics. This section first analyzes the wave transformation on underwater trenches over the idealized bathymetry and understands the wave reflection and transmission mechanisms. Thereafter, the analysis extends to study region with the proposed Sethusamudram project. 


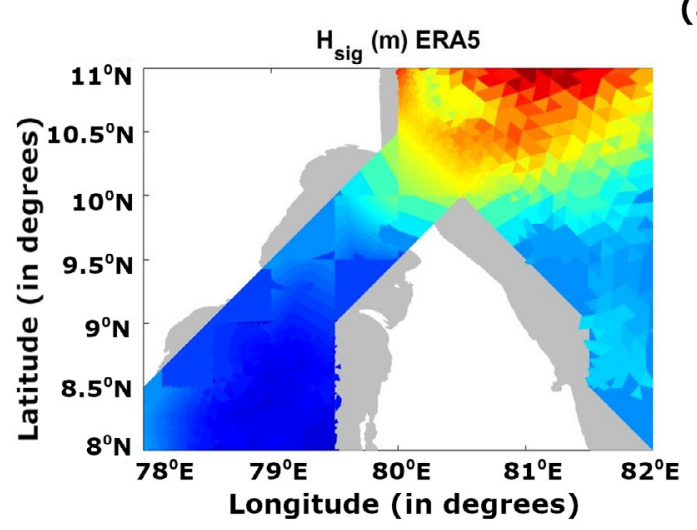

(a)
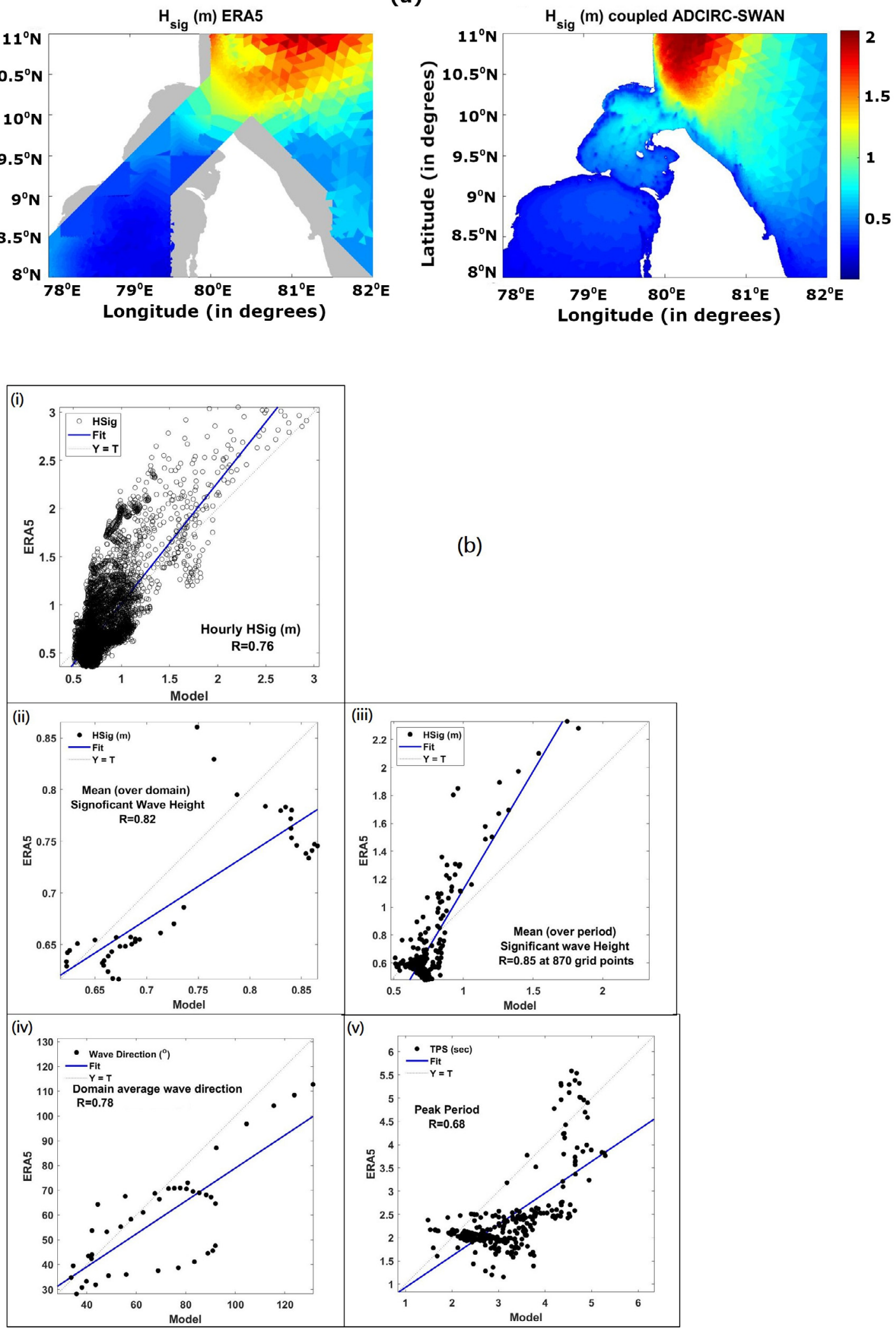

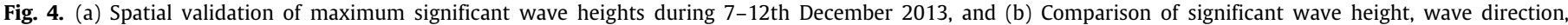
and peak period with ERA5.

\subsubsection{Wave propagation over trenches with constant bathymetry}

Impact of trench width and depth on wave transformation: Study performed numerical experiments with varying depths and widths of nearshore depressions over constant bathymetry as shown in Fig. 5a-b. The wave profile in the figures decipher that wave attenuation for deeper and wider trenches is more in the 


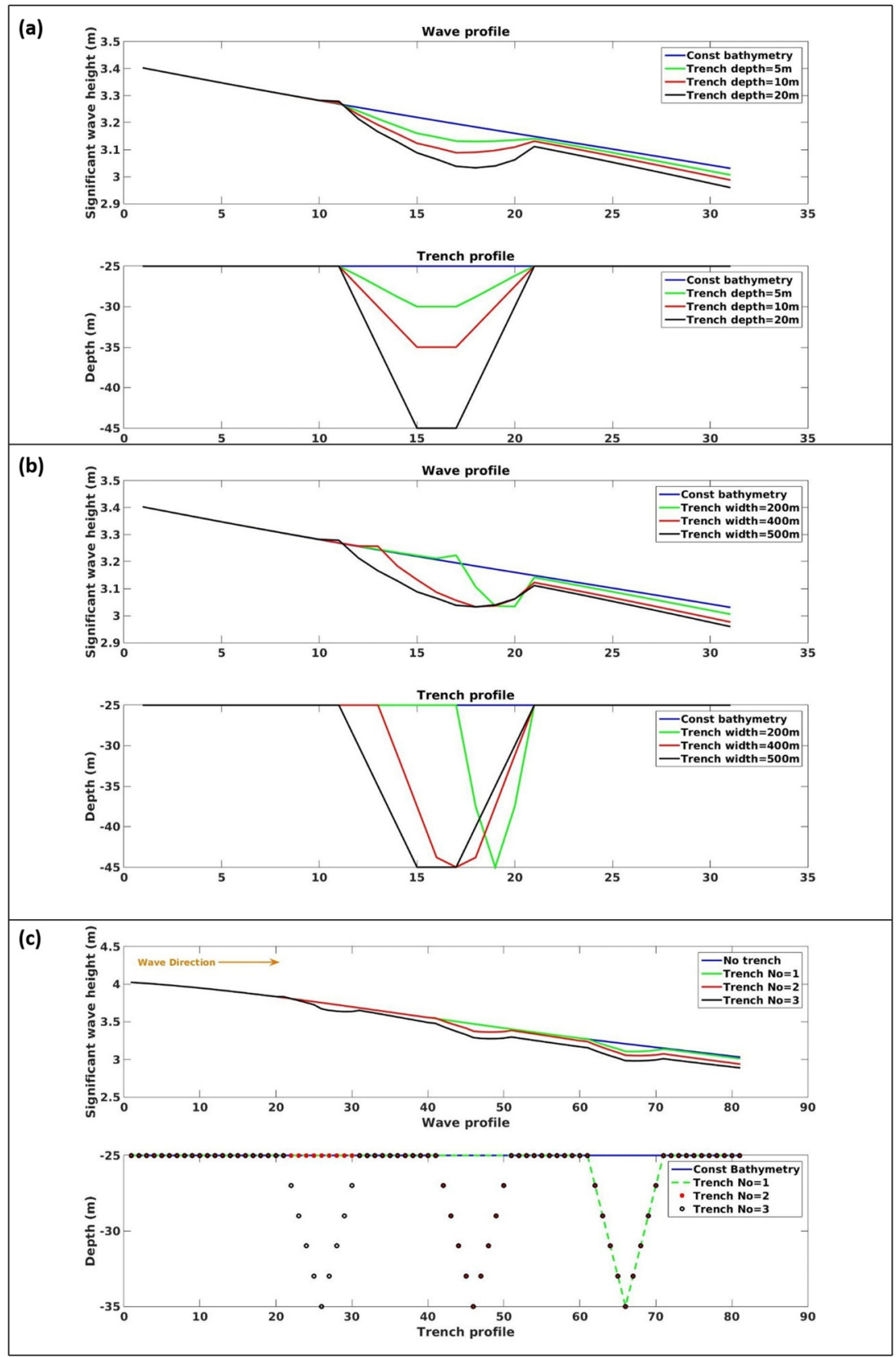

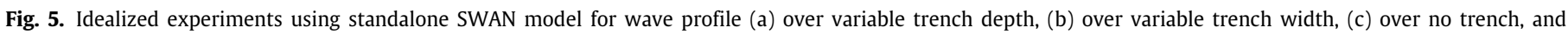
with single, double, and triple trenches, (d) over variable trench depth on sloping bathymetry, (e) over multiple trenches on sloping bathymetry.

idealized case. The wave profile almost follows the bathymetric relief; however, the reflected waves are evident along the edges of the trench. The analysis reveals that similar to breakwaters, the presence of nearshore trenches also contributes to wave reflection. Trenches with deeper and narrow geometry result in more wave reflection as shown in Fig. 5a-b.

Wave propagation in the presence of multiple trenches: Kar et al. (2018) derived the wave attenuation and reflection characteristics to be more in the case of multiple trenches. To verify the fact, the present study performed sensitivity experiments using a constant bathymetry of $25 \mathrm{~m}$ (Fig. 2). SWAN model forced using a constant significant wave height of $4.1 \mathrm{~m}$ and a wave period of $10 \mathrm{~s}$ prescribed along the offshore boundary, and the results indicate a significant wave height of $3.1 \mathrm{~m}$ at the nearshore region. However, the presence of trenches in the constant bathymetry attenuates the wave height in order of $0.1 \mathrm{~m}$ (Fig. $5 \mathrm{c}$ ). Results from numerical experiment indicate that wave attenuation increases in the presence of multiple trenches. As noticed from Fig. $5 c$, an increase in wave attenuation is evident for three trenches located in a uniform bathymetry.

3.2.2. Wave propagation on trenches over bathymetry with a gradient

Fig. 5d represents the bathymetric configuration with a uniform gradient and trenches with different water depths of $5 \mathrm{~m}$, $10 \mathrm{~m}$, and $15 \mathrm{~m}$. Numerical experiments were performed using a standalone SWAN model to understand the wave propagation characteristics on a sloping bathymetry impacted by the presence of single, double, and three trenches. The wave profile as seen in Fig. 5e depicts that the presence of trenches on a gradient reflects the waves along the leeward direction that results in increased wave heights at the eastward slope of the trench. Increased wave 


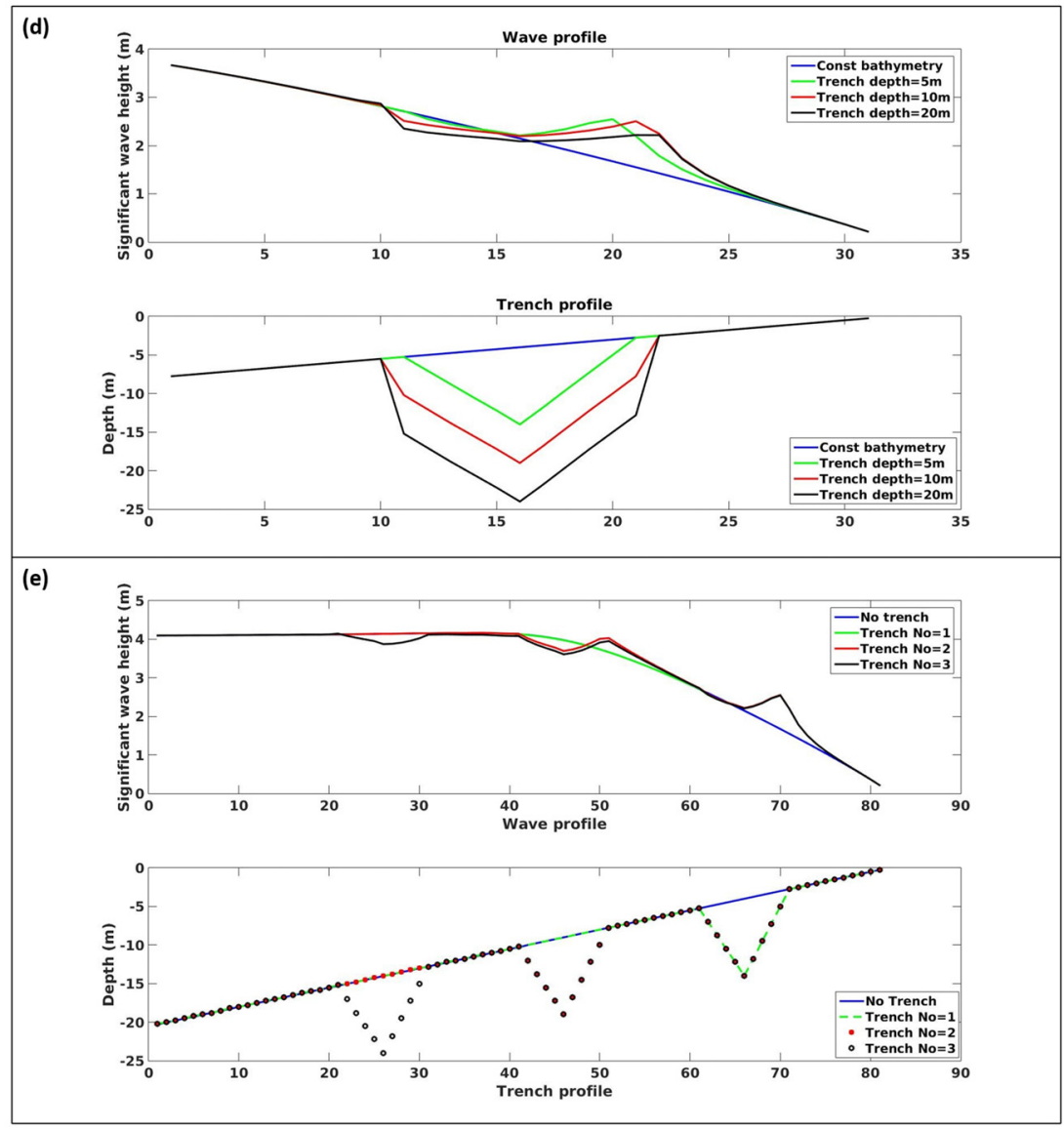

Fig. 5. (continued).

(a) Current speed $(\mathrm{m} / \mathrm{s})$ on real bathymetry

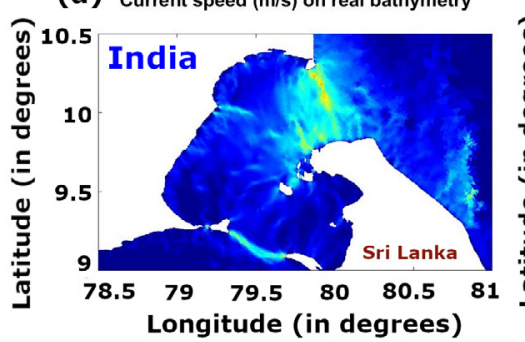

(b) Current speed $(\mathrm{m} / \mathrm{s})$ on hypothetical

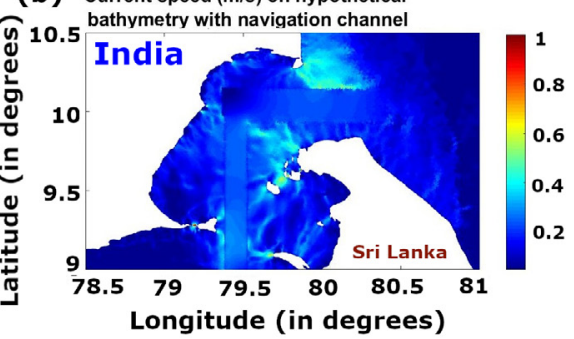

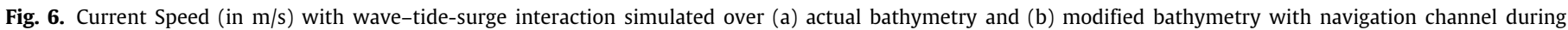
tropical cyclone Madi.

height preserves beyond the trenches when compared to the wave profile with bathymetry having gradient towards the coast and with no trench. Similar to the case with uniform bathymetry, the significant wave height does not decrease in the presence of multiple trenches on a bathymetry with a constant slope. With an increase in trench depth, the wave heights decrease, however, there is a rapid growth in wave heights at the increasing slope of the trench (Fig. 5d). Increased wave heights persist even beyond the trench location. Interestingly, the increase in wave height in the presence of trench is not found in deeper (at trench located between $20-30 \mathrm{~km}$ ) water depths (Fig. 5e). For varying depths along a wave crest results in crest traveling at different phase speed, with those part of the wave in relatively deeper waters moving faster than those in shallow water. Hence, the wave energy between the rays concentrate as they converge, resulting in increased wave height. The idealized experiment (Fig. 5) shows an increase in wave height with increase in channel depth. With increase in trench slope, wave speed decreases leading to an increase in the potential energy of waves. As a result, the wave heights increase and with a further decrease in water depth, the wave height decreases due to bottom interaction. Although, the study found no change in the wave heights along the coast, a possible change in wave heights may occur as in the case of the navigation channels or bathymetric depression near the shoreline.

3.2.3. Wave-current-surge interaction in the presence of the navigation channel

Fig. $3 c-d$ show the spatial varying extreme waves and storm tide due to changes in bathymetry and by introducing the hypothetical navigation channel (as shown in Fig. 2c). It is evident from the model simulation that the presence of navigation channel might increase the magnitude of significant wave height over this region due to localized increase in water depth (Fig. 3c). Based on the inferences obtained from experiments mentioned 
Table 2

Percentage change in storm tide and significant wave height for coastal regions estimated with cyclone Madi (2013) as the reference using actual bathymetry.

\begin{tabular}{llll}
\hline Bathymetry & \multicolumn{2}{l}{$\%$ change in coastal storm tide (significant wave height) } \\
\cline { 2 - 4 } & Madi (2013) & SLR & $\begin{array}{l}\text { 7\% intensification } \\
\text { in TC activity }\end{array}$ \\
\hline Actual bathymetry & & $0(3)$ & $10(20)$ \\
Modified bathymetry & $4(1)$ & $4(4)$ & $16(23)$ \\
with navigation channel) & & & \\
\hline
\end{tabular}

in Sections 3.2.1 and 3.2.2, waves undergo transmissions over underwater deformations on bathymetry. Wave transformation over submarine canyons (Thomson et al., 2005, 2007) show partial wave reflection due to their presence near California. In this present study, positive interference between waves transmitting through the navigation channel and waves reflecting from the continental shelf could have resulted in higher wave heights at the intersection of the two wave fronts. The analysis found that waves averaged for the coastal region (within $3 \mathrm{~m}$ of water depth) undergo around $1 \%$ transformation in magnitude in the presence of the navigation channel. Modified bathymetry resulted in $1.5 \%$ higher values in domain averaged wave height compared to simulations using the original bathymetry.

Domain averaged storm tide simulated for the modified bathymetry with navigation channel accounts about 3\% higher value than that of in case of actual bathymetry. Storm tide along the coastal belt alone rises $4 \%$ in the presence of navigation channels. The spatial distribution of storm tide deciphers a different scenario in the presence of the navigation channel (Fig. 3d). Depending on the bathymetric profile, an interesting shift in the storm surge distribution is evident (as in Fig. 3b and d). Storm tide at Indian coasts north of Palk Strait reduces, whereas the storm tides south to Palk Strait increased. The study signifies that an increase in localized water depth on modified bathymetry in presence of the navigation channel can amplify the storm tide in the surrounding regions of the Gulf of Mannar, Adam's Bridge, and Palk Bay. However, in the case of actual bathymetry, the shallow Palk Strait refrains the wave-tide propagation westward. For a better understanding, the spatial distribution of depth-averaged currents with and without the navigation channel is shown in Fig. 6a-b. Due to wave-tide-surge interaction, the flow velocity simulated with actual bathymetry is relatively higher at Palk Strait, unlike the case in the presence of the navigation channel. Presence of shallow bathymetry at Palk Strait acts similarly to a submerged breakwater that reflects waves eastward. An increase in local water depth by dredging in this region can provide an allowance for the waves and storm tide to propagate westward altering the hydrodynamics in Palk Bay and the Gulf of Mannar.

To analyze the nature of wave propagation over the trench, the reflection $K_{r}$ and transmission coefficient $K_{t}$ against the wavenumber $k h$ computed. Fig. 7a showed an oscillatory decaying profile in the reflection coefficient with an increase in wavenumber. On the contrary, Fig. 7b showed an increasing trend in the transmission coefficient with an increase in wavenumber. Fig. 7a (7b) showed lower (higher) wave reflection (transmission) in the presence of navigation channel in agreement with the mathematical studies (Kar et al., 2018; Lee and Ayer, 1981).

\subsection{Expected changes in storm surge and extreme waves}

Climate change impact have varying degrees of response at different locations around the world. Being a global phenomenon, various environmental drivers that have teleconnection with remote forcing effects and regional variabilities influence the specific location of interest. In this study, the projected climate change effects on SLR and increased tropical cyclone intensity, aimed to investigate the role of wave-current-storm surge interaction for the region of interest. Projected SLR of $0.4 \mathrm{~m}$ (expected by end of 2050 under RCP 8.5 scenario; (Kusche et al., 2016) resulted in nearly $0 \%(4 \%)$ and $3 \%(4 \%)$ respective rise in the coastal storm tide and significant wave heights when simulated over actual bathymetry (hypothetical bathymetry with navigation channel).

Fig. 8 shows the anomaly in the spatial distribution of maximum storm tide and significant wave heights obtained by considering a 7\% increase in the Madi wind field. This case study reveals that both storm tide and significant wave height conditions to enhance with an increased intensity of TC. Analysis from the model computed projections illustrate an additional rise of about $0.4 \mathrm{~m}$ in storm surge at the landfall location of cyclone Madi. In context to futuristic coastal vulnerability, a $7 \%$ rise in the intensity of Madi might induce a $10 \%$ (16\%) absolute rise in coastal storm tide over actual bathymetry (modified bathymetry with navigation channel). The study indicates that intensified cyclones and associated storm surges are prone to have a wider impact enveloping the Sri Lankan and Indian coast. A 7\% tropical cyclone intensity considering actual bathymetry and bathymetry with the navigation channel can ultimately lead to $20 \%$ and $23 \%$ absolute rise in significant wave heights along the coastal regions. Table 2 provides more details on the overall impacts of SLR, increased tropical cyclone intensity, storm surge, and extreme waves due to changes in bathymetric features relevant for the study region.

\section{Summary and conclusions}

Climate change impacts on various environmental drivers have influenced the global population in the recent past. Coastal communities have been experiencing SLR and the severity and frequency of extreme weather events. In context to the Indian coast, the geographical region bounded between south India and the Sri Lankan landmass is resilient to extreme waves and storm surges. Under normal conditions, this region lies in a tranquility zone, primarily due to its geomorphic setting in the shallow shelf, low tidal range, and the direct effect from the Southern Ocean swells and its impact along coastal regions of southeast India hindered by the presence of Sri Lankan landmass. However, the regional wave-current-surge dynamics are subject to change with the changing climate scenario and can possess a major threat to the coastal population and infrastructure. The present study performed a critical analysis on wave-current-surge interaction in normal and changing climate scenarios using a coupled ADCIRC-SWAN model with cyclone Madi (2013) as a case study. Model simulations revealed marginal variations in storm surge height of about 3\% absolute rise in significant wave heights associated with $0.4 \mathrm{~m}$ SLR. Similarly, a $7 \%$ increase in tropical cyclone intensity expected in futuristic climate change might induce an absolute rise in coastal storm surge and significant wave heights up to $10 \%$ and $20 \%$ respectively.

The intermediate water between India and Sri Lanka holds strategic importance to shipping routes upon the proposed Sethusamudram project by the Government of India. The construction of the navigation channel involves dredging activity 

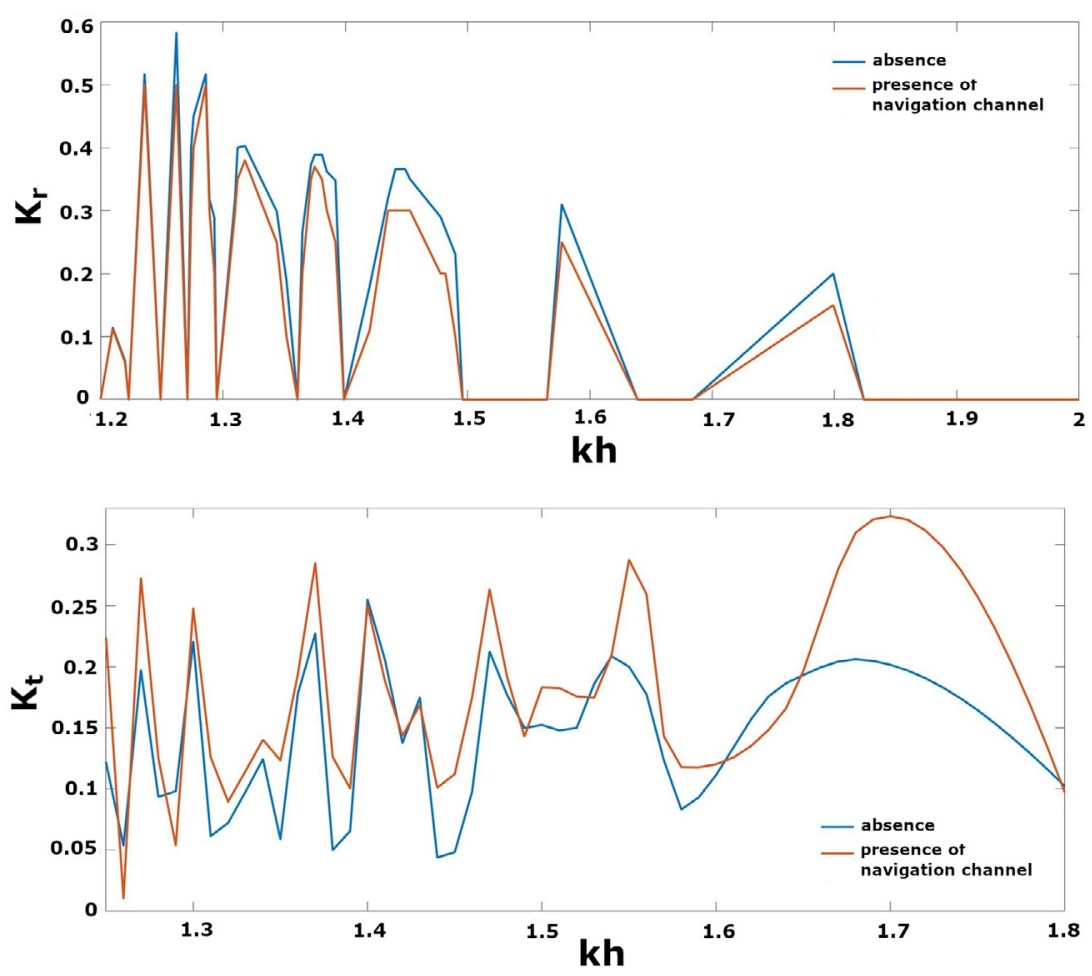

Fig. 7. (a) Reflection Coefficient $K_{\mathrm{r}}$, (b) Transmission Coefficient $K_{\mathrm{t}}$ computed for the wave propagation over actual and the modified bathymetry.
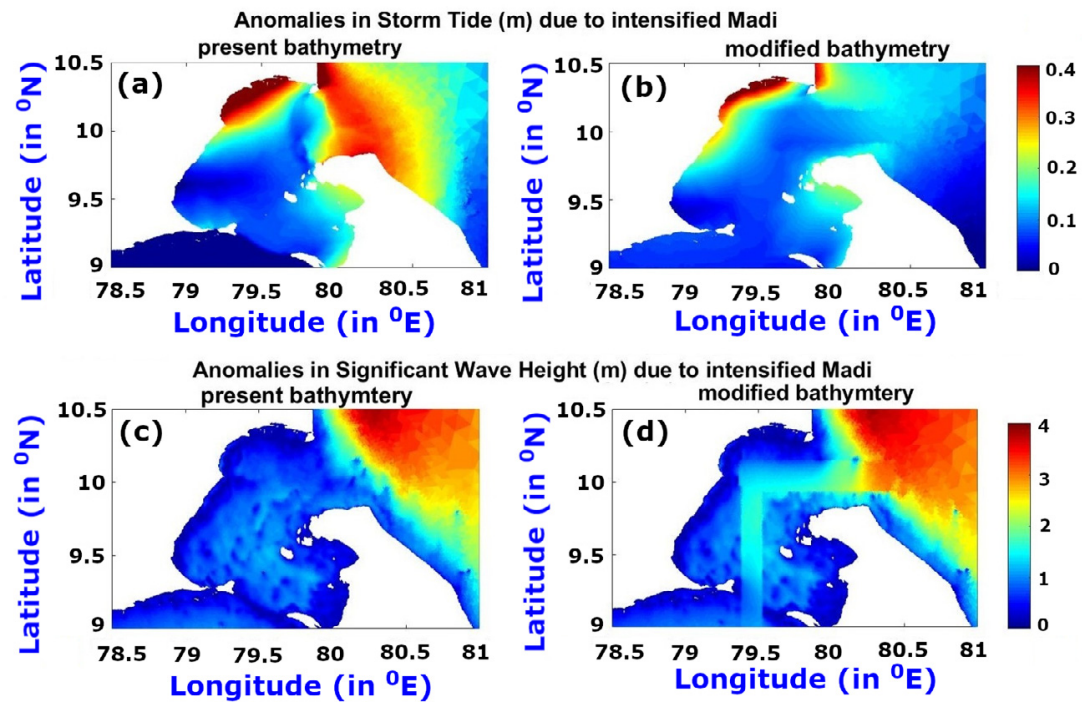

Fig. 8. (a-b) Storm tide anomalies (in m), and ( $\mathrm{c}-\mathrm{d}) H_{\text {sig }}$ (in $\mathrm{m}$ ) based on actual bathymetry and modified bathymetry with the navigational channel for $7 \%$ rise in intensity of Madi. The anomalies are computed with the storm tide and cyclonic wave scenarios during Madi (2013).

over the Gulf of Mannar, Adam's Bridge, Palk Bay, and the Palk Strait and this, in turn, will change the local bathymetry. This present study performed numerical simulations to account for the changes in wave-current-surge dynamics due to construction of the navigational channel. The present study signifies that considering a cyclone with a similar magnitude of Madi (2013) and in presence of the navigation channel would result in $4 \%$ (1\%) higher storm surge (extreme waves) in the nearby coastal regions. Interestingly, the navigation channel would shift the overall hazard potential zone further westward. Overall, by considering the navigation channel and with the impact of changing climate leading to a $7 \%$ rise in the intensity of tropical cyclones, there would be an overall $16 \%$ and $23 \%$ absolute increase in storm surge height and extreme waves in surrounding coastal regions relative to the present.

\section{CRediT authorship contribution statement}

Bishnupriya Sahoo: Conceptualization, Methodology, Software, Data curation, Writing - original draft, Visualization, Investigation, Supervision, Writing - review \& editing. Trilochan Sahoo: Data curation, Writing - original draft, Software, Validation. Prasad Kumar Bhaskaran: Conceptualization, Methodology, Software, Data curation, Writing - original draft, Visualization, Investigation, Software, Validation. 


\section{Declaration of competing interest}

The authors declare that they have no known competing financial interests or personal relationships that could have appeared to influence the work reported in this paper.

\section{Acknowledgments}

The authors sincerely thank the Department of Science and Technology (DST), Government of India for the financial support through the Centre of Excellence ( $\mathrm{CoE}$ ) in Climate Change studies established at IIT Kharagpur vide award number DST/CCP/CoE/79/ 2017(G). Model computations in the present study performed using the HPC system funded by the above project.

\section{Funding}

The authors did not receive support from any organization for the submitted work. No funding was received to assist with the preparation of this manuscript.

\section{References}

Barman, N.K., Chatterjee, S., Paul, A.K., 2016. Estimate the coastal vulnerability in the Balasore coast of India: a statistical approach. Model. Earth Syst. Environ. 2 (20), http://dx.doi.org/10.1007/s40808-015-0074-6.

Battjes, J.A., Janssen, J.P.F.M., 1979. Energy loss and set-up due to breaking of random waves. In: Proceedings of the Coastal Engineering Conference 569 (5). http://dx.doi.org/10.9753/icce.v16.32.

Behara, S., Stocken, T.V.d., Rans, G., Kodikara, K.A.S., et al., 2017. Island-wide coastal vulnerability assessment of Sri Lanka reveals that sand dunes, planted trees and natural vegetation may play a role as potential barriers against ocean surges. Global Ecol. Conserv. 12, 144-157. http://dx.doi.org/10.1016/j. gecco.2017.10.001.

Behera, H., Sahoo, T., Ng, C.O., 2018. Effect of a submerged porous plate on the hydroelastic response of a very large floating structure. J. Mar. Sci. Appl. 17, 564-577. http://dx.doi.org/10.1007/s11804-018-00056-4.

Bender, C., Miller, W., Naimaster, A., Mahoney, T., 2012. Wave modelling with SWAN+ADCIRC for the south Carolina coastal storm surge study. Coast. Eng. Proc. http://dx.doi.org/10.9753/icce.v33.waves.48.

Bhaskaran, P.K., 2010. Reliability based design method for coastal structures in shallow seas. Indian J. Geo-Mar. Sci. 39 (4), 605-615.

Bhaskaran, P.K., 2019. Challenges and future directions in ocean wave modeling - A review. J. Extrem. Events http://dx.doi.org/10.1142/S2345737619500040.

Bhaskaran, P.K., Gayathri, R., Murty, P.L.N., Subba Reddy, B., Sen, D., 2013a. A numerical study of coastal inundation and its validation for Thane cyclone in the Bay of Bengal. Coast. Eng. 83, 108-118. http://dx.doi.org/10.1016/j. coastaleng.2013.10.005

Bhaskaran, P.K., Gupta, N., Dash, M.K., 2014. Wind-wave climate projections for the Indian Ocean from satellite observations. J. Mar. Sci. Res. Dev. S11, 005. http://dx.doi.org/10.4172/2155-9910.S11-005.

Bhaskaran, P.K., Gupta, N., Dash, M.K., 2015. Wind-wave climate projections for the Indian Ocean from satellite observations. J. Mar. Sci. Res. Dev. S11, 005. http://dx.doi.org/10.4172/2155-9910.S11-005.

Bhaskaran, P.K., Kalra, R., Dube, S.K., Sinha, P.C., Rao, A.D., 2000. Extreme wave conditions over the Bay of Bengal during a severe cyclone - simulation experiment with two spectral wave models. Mar. Geod. 23 (2), 91-102. http://dx.doi.org/10.1080/01490410050030661.

Bhaskaran, P.K., Kalra, R., Dube, S.K., Sinha, P.C., Rao, A.D., 2004. Sea state hindcast with ECMWF data using a spectral wave model for typical monsoon months. Nat. Hazards 31 (2), 537-548. http://dx.doi.org/10.1023/B:NHAZ 0000023366.68304.3e

Bhaskaran, P.K., Nayak, S., Bonthu, S.R., Murty, P.L.N., Sen, D., 2013b. Performance and validation of a coupled parallel ADCIRC-SWAN model for THANE cyclone in the Bay of Bengal. Environ. Fluid Mech. 13, 601-623. http://dx.doi.org/10. 1007/s10652-013-9284-5.

Bondzie, C., Panchang, V.G., 1993. Effects of bathymetric complexities and wind generation in a coastal wave propagation model. Coast. Eng. 21, 333-366. http://dx.doi.org/10.1016/0378-3839(93)90013-X.

Cavaleri, L., Rizzoli, P.M., 1981. Wind wave prediction in shallow water: theory and applications. J. Geophys. Res. 86 (C11), 10961-10973. http://dx.doi.org/ 10.1029/JC086iC11p10961.

Copernicus Climate Change Service (C3S), 2017. ERA5: Fifth generation of ECMWF atmospheric reanalyses of the global climate. Copernicus climate change service climate data store (CDS). https://cds.climate.copernicus.eu/ cdsapp\#!/home. (Accessed 24 September 2019).
Cunha, M.G.P., 2015. The Nazaré Coast, the Submarine Canyon and the Giant Waves - A Synthesis. Coimbra Univ Coimbra, Mar Environ Sci Centre.

Das, S., Behera, H., Sahoo, T., 2016a. Flexural gravity wave motion over poroelastic bed. Wave Motion 63, 135-148. http://dx.doi.org/10.1016/j.wavemoti. 2016.02.002.

Das, S., Kar, P., Sahoo, T., Meylan, M.H., 2018. Flexural-gravity wave motion in the presence of shear current: Wave blocking and negative energy waves. Phys. Fluids 30 (10), http://dx.doi.org/10.1063/1.5052228.

Das, Y., Mohanty, U.C., Jain, I., 2016b. Development of tropical cyclone wind field for simulation of storm surge/sea surface height using numerical ocean model. Model. Earth Syst. Environ. 2 (13), http://dx.doi.org/10.1007/s40808015-0067-5.

Dietrich, J.C., Zijlema, M., Allier, P.E., Holthuijsen, L.H., Booij, N., Meixner, J.D., Proft, J.K., Dawson, C.N., Bender, C.J., Naimaster, A., Smith, J.M., Westerink, J.J., 2013. Limiters for spectral propagation velocities in SWAN. Ocean Model. 139, 85-102. http://dx.doi.org/10.1016/j.ocemod.2012.11.005.

Dietrich, J.C., Zijlema, M., Westerink, J.J., Holthuijsen, L.H., Dawson, C., Luettich, R.A., Jensen, R.E., Smith, J.M., Stelling, G.S., Stone, G.W., 2011. Modelling hurricane waves and storm surge using integrally-coupled, scalable computations. Coast. Eng. 58 (1), 45-65. http://dx.doi.org/10.1016/j.coastaleng.2010. 08.001.

Gayathri, R., Bhaskaran, P.K., Sen, D., 2015. Numerical study on storm surge and associated coastal inundation for 2009 AILA cyclone in the head Bay of Bengal. Aquat. Procedia 4, 404-411. http://dx.doi.org/10.1016/j.aqpro.2015. 02.054.

Gayathri, R., Murty, P.L.N., Bhaskaran, P.K., Srinivasa Kumar, T., 2016. A numerical study of hypothetical storm surge and coastal inundation for AILA cyclone in the Bay of Bengal. Environ. Fluid Mech. 16 (2), 429-452. http://dx.doi.org/ 10.1007/s10652-015-9434-z.

Gorrell, L., Raubenheimer, B., Elgar, S., Guza, R.T., 2011. SWAN predictions of waves observed in shallow water onshore of complex bathymetry. Coast. Eng. 58 (6), 510-516. http://dx.doi.org/10.1016/j.coastaleng.2011.01.013.

Gupta, N., Bhaskaran, P.K., Dash, M.K., 2015. Recent trends in wind-wave climate for the Indian Ocean. Current Sci. 108 (12), 2191-2201.

Gupta, N., Bhaskaran, P.K., Dash, M.K., 2017. Dipole behavior in maximum significant wave height over the southern Indian Ocean. Int. J. Climatol. 37, 4925-4937. http://dx.doi.org/10.1002/joc.5133.

Gurumoorthi, K., Venkatachalapathy, R., 2016. Spatial and seasonal trend of trace metals and ecological risk assessment along Kanyakumari coastal sediments, southern India. 269-287. http://dx.doi.org/10.7508/PJ.2016.03.003.

Hasselmann, K., Barnett, T.P., Bouws, E., Carlson, H., Cartwright, D.E., Eake, K. Euring, J.A., Gicnapp, A., Hasselmann, D.E., Kruseman, P., Meerburg, A. Mullen, P., Olbers, D.J., Richren, K., Sell, W., Walden, H., 1973. Measurements of wind-wave growth and swell decay during the joint North Sea wave project (JONSWAP). 8 (12) 95.

Hentry, C., Chandrasekar, N., Saravanan, S., 2013. Beach dynamics of Colache open coast, Kanyakumari district (SW India). Z. Geomorphol. 57 (1), 75-95. http://dx.doi.org/10.1127/0372-8854/2012/0077.

Holland, G.J., 1980. An analytic model of the wind and pressure profiles in hurricanes. Mon. Weather Rev. 108 (8), 1212-1218. http://dx.doi.org/10. 1175/1520-0493(1980)108<1212:AAMOTW>2.0.CO;2.

Jisan, M.A., Bao, S., Pietrafesa, L.J., et al., 2018. Hurricane Matthew (2016) and its impact under global warming scenarios. Model. Earth Syst. Environ. 4, 97-109. http://dx.doi.org/10.1007/s40808-018-0420-6.

Kaligatla, R.B., Manisha, Sahoo, T., 2017. Wave trapping by dual porous barriers near a wall in the presence of bottom undulation. J. Mar. Sci. Appl. 16, 286-297. http://dx.doi.org/10.1007/s11804-017-1423-9.

Kar, P., Koley, S., Sahoo, T., 2018. Scattering of surface gravity waves over a pair of trenches. Appl. Math. Model. 62, 303-320. http://dx.doi.org/10.1016/j.apm. 2018.06.002.

Kar, P., Koley, S., Sahoo, T., 2020. Bragg scattering of long waves by an array of trenches. Ocean Eng. http://dx.doi.org/10.1016/j.oceaneng.2020.107004.

Kar, P., Sahoo, T., Behera, H., 2019. Effect of Bragg scattering due to bottom undulation on a floating dock. Wave Motion 90, 121-138. http://dx.doi.org 10.1016/j.wavemoti.2019.04.011.

Kirby, J.T., Dalrymple, R.A., 1983. Propagation of obliquely incident water waves over a trench. J. Fluid Mech. 176, 95-116. http://dx.doi.org/10.1017/ S0022112083001780.

Kusche, J., Uebbing, B., Rietbroek, R., Shum, C.K., Khan, Z.H., 2016. Sea level budget in the Bay of Bengal (2002-2014) from GRACE and altimetry. J. Geophys. Res. Ocean. 121 (2), 1194-1217. http://dx.doi.org/10.1002/2015JC011471.

Lee, J.J., Ayer, R.M., 1981. Wave propagation over a rectangular trench. J. Fluid Mech. 110, 335-347. http://dx.doi.org/10.1017/S0022112081000773.

Lee, H.S., Wang, K.H., Williams, A.N., 2007. A three-dimensional modeling of multidirectional random wave diffraction by rectangular submarine pits. Ocean Eng. 34, 665-675. http://dx.doi.org/10.1016/j.oceaneng.2006.05.018.

Madsen, O.S., Poon, Y.K., Graber, H.C., 1988. Spectral wave attenuation by bottom friction: theory. 492-504. http://dx.doi.org/10.1061/9780872626874.035. 
Malik, A., Abdalla, R., 2016. Geospatial modeling of the impact of sea level rise on coastal communities: application of Richmond, British Columbia, Canada. Model. Earth Syst. Environ. 2, 146. http://dx.doi.org/10.1007/s40808-0160199-2.

Mandal, S., Datta, N., Sahoo, T., 2013. Hydroelastic analysis of surface wave interaction with concentric porous and flexible cylinder systems. J. Fluids Struct. 42, 437-455. http://dx.doi.org/10.1016/j.jfluidstructs.2013.08.012.

Millar, D.L., Smith, H.C.M., Reeve, D.E., 2007. Modelling analysis of the sensitivity of shoreline change to a wave farm. Ocean Eng. 34 (5-6), 884-890. http: //dx.doi.org/10.1016/j.oceaneng.2005.12.014.

Morelissen, R., Hulscher, S.J.M.H., Knaapen, M.A.F., Németh, A.A., Bijker, R., 2003. Mathematical modelling of sand wave migration and the interaction with pipelines. Coast. Eng. 48, 197-209. http://dx.doi.org/10.1016/S0378-3839(03) 00028-0.

Murakami, H., Vecchi, G.A., Underwood, S., 2017. Increasing frequency of extremely severe cyclonic storms over the Arabian Sea. Nat. Clim. Chang. 7 (12), 885-889. http://dx.doi.org/10.1038/s41558-017-0008-6.

Murty, P.L.N., Bhaskaran, P.K., Gayathri, R., Sahoo, B., Srinivasa Kumar, T., Subba Reddy, B., 2016. Numerical study of coastal hydrodynamics using a coupled model for Hudhud cyclone in the Bay of Bengal. Estuar. Coast. Shelf Sci. 183, 13-27. http://dx.doi.org/10.1016/j.ecss.2016.10.013.

Murty, P.L.N., Rao, A.D., Siva Srinivas, K., Rama Rao, E.P., Bhaskaran, P.K., 2019. Effect of wave radiation stress in storm surge-induced inundation: A case study for the east coast of India. Pure Appl. Geophys. http://dx.doi.org/10. 1007/s00024-019-02379-x.

Murty, P.L.N., Sandhya, K.G., Bhaskaran, P.K., Jose, F., Gayathri, R., Balakrishnan Nair, T.M., Srinivasa Kumar, T., 2014. A coupled hydrodynamic modeling system for Phailin cyclone in the Bay of Bengal. Coast. Eng. 93, 71-81. http://dx.doi.org/10.1016/j.coastaleng.2014.08.006.

Murty, P.L.N., Siva Srinivas, K., Rama Rao, E.P., Bhaskaran, P.K., Shenoi, S.S.C., Padmanabham, J., 2020. Improved cyclonic wind fields over the Bay of Bengal and their application in storm surge and wave computations. Appl. Ocean Res. http://dx.doi.org/10.1016/j.apor.2019.102048.

Nayak, S., Bhaskaran, P.K., 2014. Coastal vulnerability due to extreme waves at Kalpakkam based on historical tropical cyclones in the Bay of Bengal. Int. J. Climatol. 34, 1460-1471. http://dx.doi.org/10.1002/joc.3776.

Nayak, S., Bhaskaran, P.K., Venkatesan, 2012. Near-shore wave induced setup along Kalpakkam coast during an extreme cyclone event in the Bay of Bengal. Ocean Eng. 55, 52-61. http://dx.doi.org/10.1016/j.oceaneng.2012.07.036.

Nayak, S., Bhaskaran, P.K., Venkatesan, R., Dasgupta, S., 2013. Modulation of local wind-waves at Kalpakkam from remote forcing effects of Southern Ocean swells. Ocean Eng. 64, 23-35. http://dx.doi.org/10.1016/j.oceaneng.2013.02. 010.

Padhy, C.P., Sen, D., Bhaskaran, P.K., 2008. Application of wave model for weather routing of ships in the North Indian Ocean. Nat. Hazards 44, 373-385. http://dx.doi.org/10.1007/s11069-007-9126-1.

Parthasarathy, A., Natesan, U., 2015. Coastal vulnerability assessment: a case study on erosion and coastal change along Tuticorin, Gulf of Mannar. Nat. Hazards 75, 1713-1729. http://dx.doi.org/10.1007/s11069-014-1394-y.

Parvathy, K.G., Bhaskaran, P.K., 2017. Wave attenuation in presence of mangroves: A sensitivity study for varying bottom slopes. Int. J. Ocean Clim. Syst. 8 (3), 126-134. http://dx.doi.org/10.1177/1759313117702919.

Parvathy, K.G., Bhaskaran, P.K., 2019. Nearshore modelling of wind-waves and its attenuation characteristics over a mud dominated shelf in the head Bay of Bengal. Reg. Stud. Mar. Sci. 29, 100665. http://dx.doi.org/10.1016/j.rsma. 2019.100665.

Parvathy, K.G., Umesh, P.A., Bhaskaran, P.K., 2017. Inter-seasonal variability of wind-waves and their attenuation characteristics by mangroves in a reversing wind system. Int. J. Climatol. 37 (15), 5089-5106. http://dx.doi. org/10.1002/joc.5147.

Patra, A., Bhaskaran, P.K., 2016a. Temporal variability in wind-wave climate and its validation with ESSO-niot wave atlas for the head Bay of Bengal. Clim. Dynam. 49, 1271-1288. http://dx.doi.org/10.1007/s00382-016-3385-z.

Patra, A., Bhaskaran, P.K., 2016b. Trends in wind-wave climate over the head Bay of Bengal region. Int. J. Climatol. 36, 4222-4240. http://dx.doi.org/10.1002/ joc.4627.

Patra, A., Bhaskaran, P.K., Maity, R., 2019. Spectral wave characteristics over the head Bay of Bengal: A modeling study. Pure Appl. Geophys. http://dx.doi. org/10.1007/s00024-019-02292-3.
Plant, N.G., Edwards, K.L., Kaihatu, J.M., Veeramony, J., Hsu, L., Holland, K.T., 2009. The effect of bathymetric filtering on nearshore process model results. Coast. Eng. 56, 484-493. http://dx.doi.org/10.1016/j.coastaleng.2008.10.010.

Poulose, J., Rao, A.D., Bhaskaran, P.K., 2017. Role of continental shelf on nonlinear interaction of storm surges, tides and wind waves: An idealized study representing the west coast of India. Estuar. Coast. Shelf Sci. http: //dx.doi.org/10.1016/j.ecss.2017.06.007.

Pramanik, M.K., Biswas, S.S., Mukherjee, T., Roy, A.K., Pal, R., et al., 2015. Sea level rise and coastal vulnerability along the eastern coast of India through geo-spatial technologies. J Geophys. Remote Sens. 4, 145. http://dx.doi.org/ 10.4172/2169-0049.1000145.

Ris, R.C., Holthuijsen, L.H., Booij, N., 1999. A third-generation wave model for coastal regions 2. Verification. J. Geophys. Res. Ocean 104 (C4), 7667-7681. http://dx.doi.org/10.1029/1998jc900123.

Rose, L., Bhaskaran, P.K., 2017a. Tidal propagation and its non-linear characteristics in the head Bay of Bengal. Estuar. Coast. Shelf Sci. 188, 181-198 http://dx.doi.org/10.1016/j.ecss.2017.02.024.

Rose, L., Bhaskaran, P.K., 2017b. Tidal asymmetry and characteristics of tides at the head of the Bay of Bengal. Q. J. R. Meteorol. Soc. 143, 2735-2740. http://dx.doi.org/10.1002/qj.3122.

Sahoo, B., Bhaskaran, P.K., 2016. Assessment on historical cyclone tracks in the Bay of Bengal, east coast of India. Int. J. Climatol. 36 (1), 95-109. http://dx.doi.org/10.1002/joc.4331.

Sahoo, B., Bhaskaran, P.K., 2017. Coastal vulnerability index and its projection for Odisha coast, east coast of India. World Academy of Science, Engineering and Technology, 126. Int. J. Environ. Ecol. Eng. 11, 519-523. http://dx.doi. org/10.5281/zenodo.1131075.

Sahoo, B., Bhaskaran, P.K., 2018. A comprehensive data set for tropical cyclone storm surge-induced inundation for the east coast of India. Int. J. Climatol. 38 (1), 403-419. http://dx.doi.org/10.1002/joc.5184.

Sahoo, B., Jose, F., Bhaskaran, P.K., 2019. Hydrodynamic response of Bahamas archipelago to storm surge and hurricane generated waves - A case study for Hurricane Joaquin. Ocean Eng. 184, 227-238. http://dx.doi.org/10.1016/j. oceaneng.2019.05.026.

Samiksha, V., Vethamony, P., Antony, C., Bhaskaran, P.K., Balakrishnan Nair, T.M. 2017. Wave-current interaction during Hudhud cyclone in the Bay of Bengal. Nat. Hazards Earth Syst. Sci. 17, 2059-2074. http://dx.doi.org/10.5194/nhess17-2059-2017.

Singh, K.S., Albert, J., Bhaskaran, P.K., Alam, P., 2021. Assessment of extremely severe cyclonic storms over Bay of Bengal and performance evaluation of ARW model in the prediction of track and intensity. Theor. Appl. Climatol. http://dx.doi.org/10.1007/s00704-020-03510-y.

Sreelakshmi, S., Bhaskaran, P.K., 2020a. Regional wise characteristic study of significant wave height for the Indian Ocean. Clim. Dyn. 1-19. http://dx. doi.org/10.1007/s00382-020-05186-6.

Sreelakshmi, S., Bhaskaran, P.K., 2020b. Spatio-temporal distribution and variability of high threshold wind speed and significant wave height for the Indian Ocean. Pure Appl. Geophys. 1-17. http://dx.doi.org/10.1007/s00024020-02462-8.

Thomson, J., Elgar, S., Herbers, T.H.C., 2005. Reflection and tunneling of ocean waves observed at a submarine canyon. Geophys. Res. Lett. 32, L10602. http://dx.doi.org/10.1029/2005GL022834.

Thomson, J., Elgar, S., Herbers, T.H.C., Raubenheimer, B., Guza, R.T. 2007. Refraction and reflection of infragravity waves near submarine canyons. J. Geophys. Res. Ocean 112, C10009. http://dx.doi.org/10.1029/2007JC004227.

Umesh, P.A. Bhaskaran, P.K. Sandhya, K.G., Balakrishnan Nair, T.M. 2019. Numerical simulation and preliminary analysis of spectral slope and tail characteristics using nested WAM-SWAN in a shallow water application off Visakhapatnam. Ocean Eng. 173, 268-283. http://dx.doi.org/10.1016/j. oceaneng.2018.12.034.

Vlasenko, V., Stashchuk, N., 2007. Three-dimensional shoaling of large-amplitude internal waves. J. Geophys. Res. Ocean 112, C11018. http://dx.doi.org/10. 1029/2007JC004107.

Williams, J.J., Esteves, L.S., Rochford, L.A., 2015. Modelling storm responses on a high-energy coastline with XBeach. Model. Earth Syst. Environ. 1 (3), http://dx.doi.org/10.1007/s40808-015-0003-8.

Xie, D.-M., Zou, Q.-P., Cannon, J.W., 2016. Application of SWAN+ADCIRC to tidesurge and wave simulation in Gulf of Maine during Patriot's Day storm. Water Sci. Eng. 9, 31-41. http://dx.doi.org/10.1016/j.wse.2016.02.00. 